\title{
In vitro development of pig preantral follicles
}

\author{
E. E. Telfer \\ Institute of Cell and Molecular Biology, University of Edinburgh, King's Buildings, \\ Mayfield Road, Edinburgh EH9 3JR, UK
}

\begin{abstract}
A limiting factor to realizing the full potential of many of the new reproductive techniques is the lack of abundant numbers of fertilizable oocytes. This problem could be addressed by using the large source of oocytes available from preantral and primordial follicles by developing systems for in vitro growth. In vitro systems that use early growing follicles as a source of oocytes have been developed for laboratory species and these have been successful in producing live young. If successful, in vitro growth in association with in vitro maturation (IVM) and cryopreservation would optimize in vitro production systems. In vitro growth systems that support the growth of pig preantral follicles have been developed and have been successful in producing meiotically competent oocytes but, to date, no live young have been produced. However, these systems remain to be characterized and their main application is as experimental models to study the processes of early oocyte and follicle development. This review provides an overview of culture systems that have been developed for domestic species and discusses how these are furthering our basic knowledge of early follicular development, as well as considering the benefits and potential problems associated with in vitro growth systems.
\end{abstract}

\section{Introduction}

The ability to grow mature oocytes from immature oocytes in vitro is the ambition of many people involved in animal production. The idea of harvesting immature oocytes for growth in vitro is not a new one and over the past decade techniques have been developed for isolating and culturing preantral follicles from a range of rodent species (Roy and Greenwald 1985, 1989; Eppig and Schroeder, 1989; Torrance et al., 1989; Nayudu and Osborn, 1992; Spears et al., 1994; Cortvrindt et al., 1996). The limited success of the rodent system for production of viable offspring (Eppig and Schroeder, 1989) has resulted in many attempts to develop similar methods for applications in humans (Abir et al., 1997; Wright et al., 1999) and domestic species (for reviews see Telfer, 1998; Telfer et al., 1999; Van den Hurk et al., 2000). Progress has been slow in developing culture systems to support oocyte development from non-rodent species. Indeed, follicle culture promises much but so far there has been no real progress in applying these techniques to animals with follicles that undergo a long period of growth. Culture conditions for these species will be complex and dynamic, as they must promote oocyte growth, acquisition of developmental competence and appropriate genomic 
maturation (genomic imprinting). The slow progress in developing culture systems has been due mainly to a lack of knowledge of the basic mechanisms that control follicle and oocyte development in these species. Therefore, the main application of in vitro growth systems at this time is as experimental models to gain valuable insight into factors regulating follicle and oocyte development.

\section{Selection of follicles for in vitro growth}

The ovarian follicle, which comprises an oocyte and its companion somatic cells, is the functional unit of the mammalian ovary. By or shortly after the birth of female mammals there is a large store of primordial follicles that constitutes the only reserve of germ cells in the postnatal ovary. The number of primordial follicles varies with age, species and breed but, in general, larger species have more follicles than do smaller species (Jones and Krohn, 1961; Gosden and Telfer, 1987a,b). By the time the female reaches puberty about $75 \%$ of the original store of primordial follicles will have degenerated (Erickson, 1966; Gosden and Telfer, 1987b). This loss represents an enormous wastage of genetic material, but even after puberty only a small number of follicles will ever be used and the rest will degenerate at the antral stage of development (Faddy et al., 1987; Gosden and Telfer, 1987b). Therefore, there are large numbers of immature (primordial and preantral) follicles at all ages that are a potential source of follicles for in vitro growth.

It is not known whether all immature follicles are capable of development in vitro or whether there is an optimal population that can be selected. However, primordial and early preantral (primary) follicles are a more homogeneous group than later preantral and antral follicles, as at these developmental stages there is a low rate of degeneration. The degree of apoptotic cell death in the granulosa cells of pig follicles ranging from $100 \mu \mathrm{m}$ to $3.3 \mathrm{~mm}$ in diameter has been examined (F. Ghafari and E. E. Telfer, unpublished) and it was found that in follicles $\leqslant 500 \mu \mathrm{m}$ in diameter there is little apoptotic cell death but, thereafter, $>50 \%$ of follicles show signs of apoptosis. Similar results were found using bovine follicles, in which about $90 \%$ of antral follicles were already undergoing apoptotic cell death at the time of isolation, whereas $<10 \%$ of isolated preantral and early antral follicles showed any signs of apoptosis (Telfer et al., 1998). Thus, to obtain maximum numbers of follicles that have not been compromised it is best to isolate primordial or early preantral follicles.

\section{Methods of isolating immature follicles}

\section{Primordial follicles}

Primordial follicles are the most abundant population of oocytes in the ovary at any age (Gosden and Telfer, 1987b), but they are also the follicles about which least is known and they are difficult to isolate. Primordial follicles can be isolated from the ovaries of rodents and piglets using proteolytic enzyme digestion (Greenwald and Moor, 1989), but the enzymatic techniques lead to degradation of the basement membrane and result in detachment of granulosa cells from the oocyte. There are as yet no reliable methods for isolating intact primordial follicles and so most of the culture work involving primordial follicles has relied on the isolation of clumps or slices of ovarian cortex, as these sections are composed almost entirely of primordial follicles (Braw-Tal and Yossefi, 1997; Fortune et al., 1998). The isolation and culture of primordial follicles remains the ideal but it is likely to be some time before this can be achieved and a more realistic starting point is preantral follicles. 


\section{Preantral follicles}

Several methods have been developed for isolation of preantral follicles from rodent ovaries, which involve either tissue disaggregation by enzymes or microdissection. Enzymatic digestion using collagenase and DNase has been used successfully to isolate follicles from mice (Eppig and Schroeder, 1989; Torrance et al., 1989; Eppig and Telfer, 1993), hamsters (Roy and Greenwald, 1985) and rats (Daniel et al., 1989). Such methods have allowed large numbers of early developing preantral follicles to be collected from rodents for culture to the stage at which the oocytes can resume meiotic maturation and be fertilized (Eppig, 1994; Eppig and O'Brien, 1998). However, the enzyme treatment compromises the integrity of the basement membrane and detaches adherent theca cells so these units are actually granulosa cell-oocyte complexes and not intact follicles. A microdissection technique has to be used to isolate intact follicles from rodent ovaries (Spears et al., 1994); this is relatively straightforward as the stromal tissue is soft.

The large-scale isolation of preantral follicles from domestic species has been more difficult to achieve (for reviews see Telfer, 1996; Telfer et al., 1999; Van den Hurk et al., 2000). The ovaries of domestic species are fibrous in nature and, therefore, techniques that work in rodents cannot be readily applied. Proteolytic enzymes have been used to isolate follicles from pig (Telfer, 1996) and horse (Telfer and Watson, 2000) ovaries but the most effective and reliable method for isolating preantral follicles from domestic species is by microdissection from ovarian cortical slices (McCaffery et al., 2000) (Fig. 1). The most effective method for isolating preantral follicles from pig ovaries is by microdissection from cortical slices, as this method allows the isolation of morphologically 'normal' follicles with intact basement membranes and maintains theca-granulosa-oocyte interactions (Van den Hurk et al., 1998). The disadvantage of this method of isolation is that it is slow, labour intensive and provides a relatively low yield.

\section{In vitro growth systems}

Several culture systems have been devised that support development in vitro of immature follicles from rodents. The most successful system in terms of production of developmentally competent oocytes is that developed by Eppig and Schroeder (1989). In this system, granulosa cell-oocyte complexes from immature mice can be grown on a collagen matrix under serumfree conditions for up to 12 days. During this growth period many of the oocytes acquire developmental competence. Indeed, it has been calculated that using this technique of in vitro growth and subsequent IVM it is possible to obtain four times as many blastocysts per animal as can be produced by IVM of in vivo-derived oocytes (Eppig and O'Brien, 1998). Although these results are impressive, they should be treated with caution, as a high rate of blastocyst formation does not predict the rate of successful development to live young.

The development of an in vitro system that supports oocyte and follicle growth in domestic species is much more ambitious because oocyte development occurs over a much longer time compared with that in laboratory animals, and follicles are large (Fig. 2). The ideal in vitro system for oocyte growth would be a system in which isolated oocytes could achieve growth and developmental competence in defined media without the follicle unit. However, oocyte growth is dependent upon gap junction-mediated communication between the oocyte and its companion granulosa cells, and the rate of growth is related directly to the number of granulosa cells coupled to the oocyte (Herlands and Schultz, 1984). Therefore, the intimate physiological connections between oocytes and somatic cells within the follicle are essential for normal development of the oocyte. Alternatively, the next best option would be to culture 


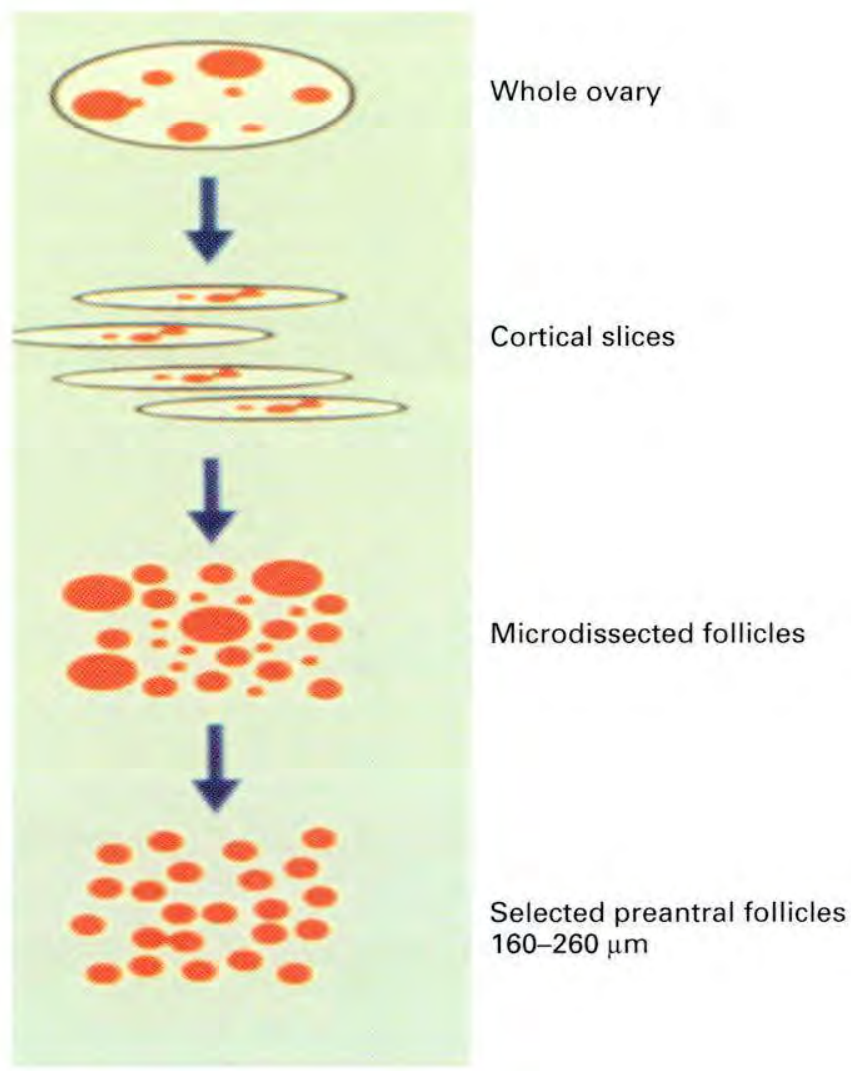

Fig. 1. Diagrammatic representation of microdissection technique for isolating pig preantral follicles. Ovaries are sliced into cortical sections (avoiding large antral follicles as much as possible). Preantral follicles are dissected from the surrounding stroma using needles and then selected by size $(160-260 \mu \mathrm{m}$ in diameter).

granulosa cell-oocyte complexes similar to those described above (Eppig and Schroeder, 1989), in which the whole follicle unit is not required for the oocyte to acquire developmental competence. To date, culture of granulosa cell-oocyte complexes has not been successful for domestic species and the whole follicle unit appears to be required for at least part of the culture period. Methods for culturing intact ovarian follicles have been developed in rodent systems (Nayudu and Osborn, 1992; Spears et al., 1994) and the advantage of these methods is that they can provide valuable information about the interaction of all components of the follicle unit.

Culture systems that support some elements of oocyte and follicle growth in follicles from cattle (Gutierrez et al., 2000; McCaffrey et al., 2000), pigs (Hirao et al., 1994; Telfer et al., 2000; Wu et al., 2000) and sheep (Cecconi et al., 1999; Newton et al., 1999) have been developed (Telfer, 1998; Van den Hurk et al., 2000). Most of these systems are at the stage of defining conditions for the early stages of follicle growth and all use an intact follicle unit. Systems to support the development of pig oocytes are more advanced than those for other large animal species (Hirao et al., 1994; Telfer et al., 2000; Wu et al., 2000) (Fig. 3). Oocytes from pig 


\begin{tabular}{|c|c|c|c|c|c|}
\hline & Primordial & $\begin{array}{c}\text { Primary } \\
\text { preantral }\end{array}$ & $\begin{array}{l}\text { Secondary } \\
\text { preantral }\end{array}$ & Antral & $\begin{array}{l}\text { Late } \\
\text { antral }\end{array}$ \\
\hline Mouse & $\frac{18}{120}$ & $\rightarrow \frac{50}{5 d}$ & $\longrightarrow 2 \mathrm{da}$ & 70 & $\rightarrow^{75}$ \\
\hline Cow & - 20 & $\rightarrow 45$ & $\underset{\text { days }}{\longrightarrow}$ & $\rightarrow 100$ & $\underset{\text { ays }}{\longrightarrow}$ \\
\hline Pig & $\quad 32$ & $\underset{\text { s }}{\longrightarrow} \frac{68}{26}$ & $\underset{\text { ays }}{\longrightarrow}$ & $\underset{\text { ays }}{\longrightarrow}$ & $\underset{\text { ays }}{\longrightarrow}$ \\
\hline
\end{tabular}

Fig. 2. Oocyte diameters in micrometres $(\mu \mathrm{m})$ (top line) for each stage of follicle development and time taken to reach each stage (bottom line) for mice, cows and pigs.

Before culture

Dissected manually (a)

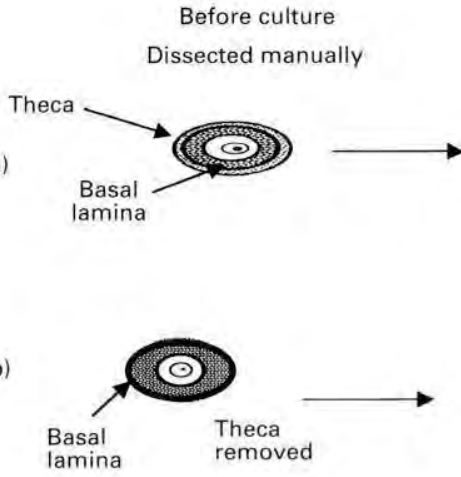

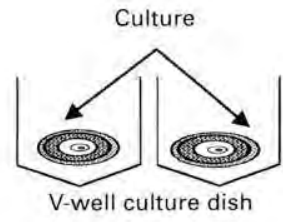

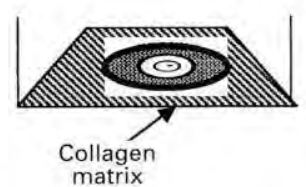

After culture
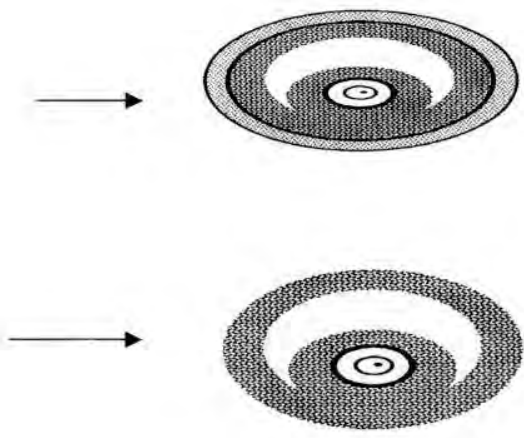

Fig. 3. Diagrammatic representation of follicle culture systems for pig preantral follicles. (a) Intact follicles (210-260 $\mu \mathrm{m}$ in diameter) are microdissected and placed in individual culture wells. During culture, antral formation occurs and in the presence of serum approximately $19 \%$ of the oocytes recovered are capable of reaching metaphase II (Telfer et al., 2000). (b) Theca cells are removed and follicles are cultured in a supported three-dimensional collagen matrix (Hirao et al., 1994). Antral formation occurs during culture and approximately $40 \%$ of the oocytes that reach $110 \mu \mathrm{m}$ in diameter after 16 days in culture reach metaphase II.

preantral follicles have been grown within a collagen gel matrix and some acquired meiotic competence once they reached a diameter of approximately $100 \mu \mathrm{m}$ (Hirao et al., 1994). A culture period of 16 days was required to achieve this level of growth and even then only $3.5 \%$ of the complexes cultured developed an oocyte with a diameter $>110 \mu \mathrm{m}$ and only $1.3 \%$ of oocytes from the initially cultured follicular structures were capable of reaching metaphase II after IVM (Hirao et al., 1994). This low rate of success to resume and progress in meiotic maturation will be the result of many factors, but the principal factors are likely to be: (i) the selection and stage of follicles that start the culture; and (ii) the culture conditions.

Telfer et al. (2000) cultured pig preantral follicles for up to 20 days and demonstrated that when follicles were cultured in serum conditions, meiotically competent oocytes could be harvested. The ability to reach the metaphase II stage after in vitro growth was dependent on the starting size of the follicle and the presence of serum in the medium. All oocytes that 
acquired meiotic competence were derived from follicles that started the culture at a diameter of $210-260 \mu \mathrm{m}$ and were cultured in the presence of serum. Oocytes derived from follicles that were $160-210 \mu \mathrm{m}$ in diameter at the start of culture were unable to reach metaphase II, whether they were cultured with or without fetal calf serum (FCS). This finding shows that the development of meiotic competence during in vitro growth is dependent on the starting population of follicles and the culture conditions, with the presence of serum factors being beneficial. Clearly, it would be more beneficial to have a serum-free culture system so that conditions can be defined. One of the difficulties with a serum-free culture system has been the high degree of apoptosis that occurs under these conditions; however, addition of ascorbic acid on a daily basis to serum-free medium prevents apoptosis in cultured bovine (Thomas et al., 2001) and pig (M. Bark and E. E. Telfer, unpublished) follicles.

$\mathrm{Wu}$ et al. (2000) reported that isolated pig preantral follicles (range 200-310 $\mu \mathrm{m}$ in diameter) have been cultured for 4 days and that after this period a proportion of oocytes were capable of maturation and fertilization, and blastocysts were produced. This study reported that optimum conditions for oocyte development during this short culture period were when three follicles were cultured per well in North Carolina State University 23 medium (NCSU 23) containing $7.5 \%$ pig serum and $1.5 \mathrm{ng} \mathrm{FSH} \mathrm{ml}^{-1}$. Under these conditions, $68 \%$ of cumulus-oocyte complexes (COCs) were recovered for IVM and oocyte maturation rates were $51 \%$, with $13 \%$ of oocytes developing to blastocysts after fertilization. The growth rate reported by $\mathrm{Wu}$ et al. (2000) is exceptionally fast, as the equivalent development in vivo would take several weeks. Such an extreme acceleration of oocyte development in vitro has not been observed in any other species and it is not known whether normal development occurred (Wu et al., 2000).

From all the culture systems that have been developed for pigs and other domestic species it is emerging that the maintenance of cellular interactions between the oocyte and granulosa cells, and the granulosa cells and theca cells, is important for oocyte development in vitro. The culture systems reported by Hirao et al. (1994) and Telfer et al. (2000) show evidence of antral formation after a few days in culture (Fig. 4a) and that the connections between the differentiated cumulus cells and oocyte remain intact during culture (Hirao et al., 1994; Fig. 4b). Meiotic and cytoplasmic maturation of oocytes grown in vitro will be unsuccessful if the somatic cells fail to maintain their interaction with the oocyte and undergo normal differentiation during in vitro growth of follicles. A greater understanding of oocyte-granulosa cell interactions and theca-granulosa cell interactions is required to improve culture systems for follicle and oocyte development.

\section{Development of markers to evaluate oocyte and follicle quality}

A major concern about accelerating the rate of oocyte development in vitro is whether this leads to the development of abnormal oocytes. Oocyte development is co-ordinated with somatic cell development and so requires developmentally regulated signals; a culture system may interfere with normal signalling pathways. Non-invasive markers are required to determine the developmental potential of in vitro-grown oocytes to improve culture systems for follicles and oocytes from pigs and other domestic species. Ideally, cellular markers of somatic cell differentiation and oocyte development would be used that could be related to normal in vivo development. There are various candidate markers such as intra-ovarian growth factors (insulin-like growth factors (IGFs), activins and inhibins) and oocyte-specific factors such as growth differentiation factor 9 (GDF-9). These factors are all essential for early follicular development and their pattern of expression is likely to give some clue as to the developmental status of the follicle or oocyte. However, the presence or absence of any of 

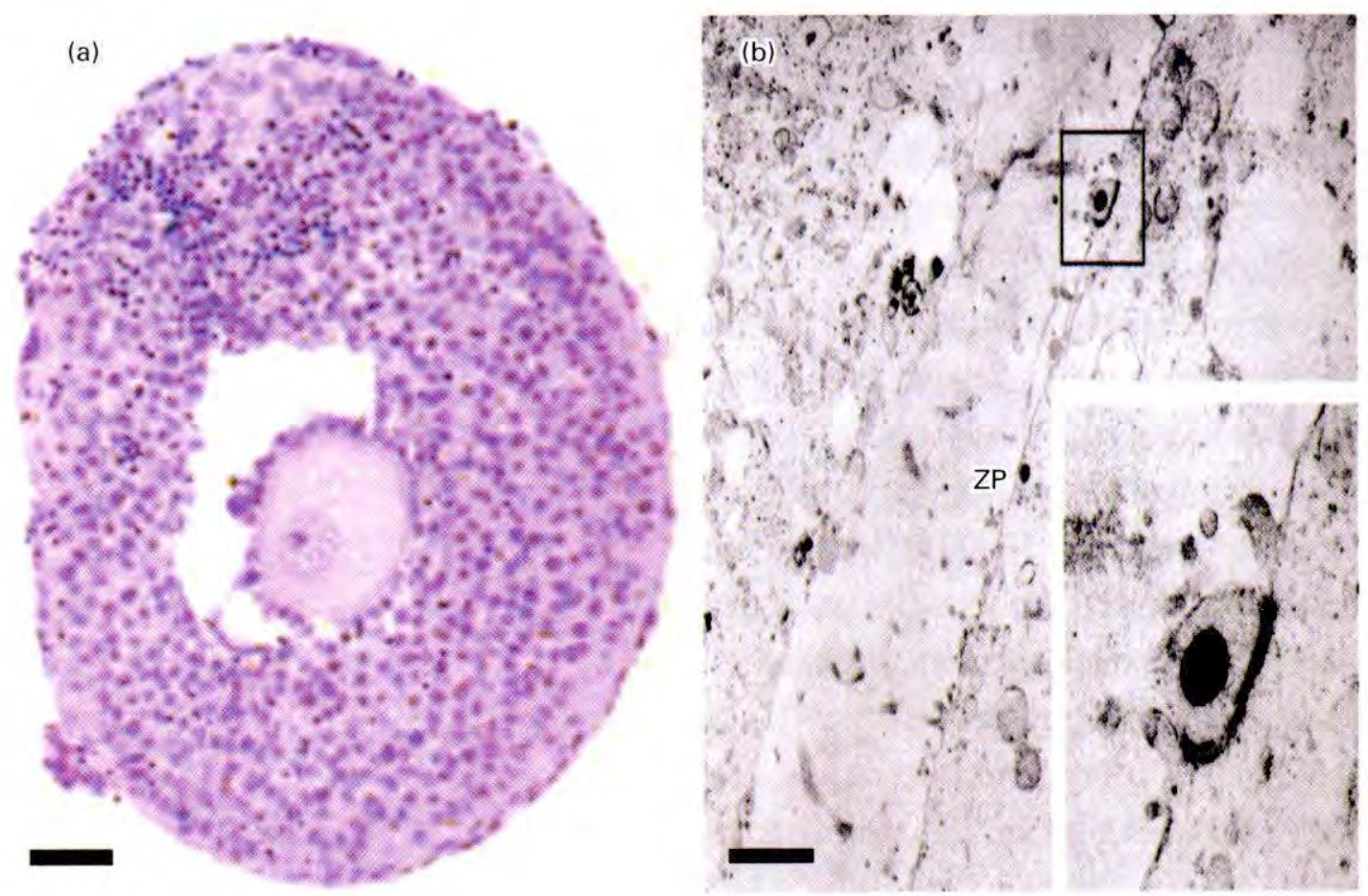

Fig. 4. (a) Histological section of pig preantral follicle after 6 days of culture. Note antral formation and detachment of the theca layer. (b) Electron micrograph of a pig oocyte cultured for 16 days in vitro. Reproduced from Hirao et al. (1994). Note the presence of a contact (inset) between the oocyte and cumulus cell process that traverses the zona pellucida (ZP). Scale bars represent (a) $50 \mu \mathrm{m}$ and (b) $20 \mu \mathrm{m}$.

these factors at any single time point is unlikely to provide information on the health of an oocyte or follicle.

The development of oocytes in vitro to a stage at which they can support normal embryonic development is dependent on the oocyte reaching the appropriate stage of development to respond to the endocrine and paracrine signals responsible for the induction of maturation. In pigs, cattle and sheep this will be over a period of at least 28 days. Therefore, some noninvasive indicator of follicle health is required. When follicles are being monitored individually in vitro, medium can be monitored at regular intervals and, therefore, any secreted factors that might indicate follicle or oocyte health could be measured easily.

In our recent studies, we have been examining the secretion of matrix metalloproteinases (MMP-2 and -9) and tissue inhibitors of metalloproteinases (TIMP-1 and -2) as markers of follicle health. During follicular growth, maintenance of the follicle wall is facilitated by MMPs. MMPs are zinc- and calcium-dependent enzymes that are capable of degrading the protein components of the extracellular matrix. MMPs are regulated by TIMPs and are also responsible for the reconstruction of the follicle wall at the time of ovulation, and during corpus luteum formation and development (Zhao and Luck, 1996). The main follicular sources of MMPs and TIMPs are thought to be the granulosa and theca cells (Smith et al., 1994; Zhao and Luck, 1996), but TIMP activity has also been found in oocytes (Bagavandoss, 1998). Balanced production of MMPs and TIMPs is essential for normal follicular development; therefore, their secretion pattern during culture might provide evidence of 
follicle or oocyte health. Our studies indicate that there is a relationship between the secretion patterns of MMP-2, MMP-9, TIMP-1 and TIMP-2, and the morphological criteria of health status of the follicle or oocyte (McCaffery et al., 2000).

The secretion of MMP-9, TIMP-1 and TIMP-2 has been correlated with morphologically healthy follicles (McCaffery et al., 2000). These factors may be useful in assessing follicle viability during prolonged cultures; however, the ultimate test of whether oocyte development in vitro has progressed normally is whether live young are produced after fertilization.

\section{Future prospects and problems}

The development of follicle culture systems has allowed many studies to be carried out on the basic mechanisms of oocyte and follicle development. Rodent culture systems have provided information on factors secreted by oocytes, which led to the discovery of GDF-9, an oocytespecific factor that regulates early follicle development (Vanderhyden et al., 1992). The development of systems for domestic species is leading to the elucidation of some basic mechanisms of early oocyte and follicle development (McCaffrey et al., 2000; Thomas et al., 2001). Clearly, there is potential to develop these culture systems from the experimental model phase to the production phase but there are serious concerns that immature oocytes harvested for in vitro growth may be developmentally compromised and may result in the production of unhealthy offspring.

It is now clear that the long-term health of an individual can be influenced by fetal-maternal interactions (Nathanielsz, 1999) and that any factors that stress the preimplantation embryo could adversely affect fetal-maternal interactions, resulting in problems for the offspring. Some assisted reproductive technologies that involve the culture of oocytes or embryos can lead to problems in the fetus or offspring. High birth weights and abnormal fetal development have been observed in calves and lambs produced by IVM and IVF, or by in vitro culture of embryos (Behboodi et al., 1995). The abnormalities observed were associated initially with the technique of nuclear transfer (Willadsen et al., 1991) but it is now clear that these features can arise from in vitro culture of embryos (Walker et al., 1992, 1996). These features have been characterized as large offspring syndrome (Walker et al., 1996; Thompson, 1997; Young et al., 1998; Sinclair et al., 1999), which is also associated with an increased rate of abortion, increased duration of gestation, physical abnormalities and increased mortality and morbidity (Walker et al., 1996; Thompson, 1997).

The identification of a link between embryo manipulation and various abnormalities raises the question of the safety of these techniques and it is not known whether using immature oocytes for in vitro production would exacerbate this. Mice produced from preantral follicles grown in vitro appear to be normal at birth but no follow-up studies of any mice produced in this way have been conducted. There is one report that a single mouse (indeed, to date the only animal produced in such a way) produced from a primordial follicle grown in vitro (Eppig and O'Brien, 1996) suffered from obesity, liver problems and neurological damage in adulthood (Eppig and O'Brien, 1998). Whether these problems are in any way connected to the in vitro production methods or are entirely random cannot yet be answered, but it does raise questions as to the safety of these techniques and suggests that we should proceed with caution from the experimental application to production using these techniques. The application of new molecular techniques to screen early oocytes and embryos for normal expression patterns will be critical to the development and application of in vitro growth techniques. The use of appropriate micro-arrays will be instrumental to ensure the generation of embryos with normal expression patterns and should increase the likelihood of obtaining normal offspring. 


\section{Conclusion}

The culture of immature follicles holds much promise. In conjunction with cryopreservation techniques, culture of immature follicles has the potential to optimize in vitro production systems. However, our understanding of the conditions that allow normal development of oocytes is still at an early stage. The main benefits of these culture systems are in obtaining information to improve our understanding of the mechanisms that control oocyte growth, accumulation of regulatory factors and acquisition of competence to undergo fertilization and embryogenesis.

The author would like to acknowledge grant support from BBSRC, MAFF, MRC, The Wellcome Trust, Pig Improvement Company and MLC.

\section{References}

Abir R, Franks S, Mobberley MA, Moore PA, Margara RA and Winston RML (1997) Mechanical isolation and in vitro growth of preantral and small antral human follicles Fertility and Sterility $68682-688$

Bagavandoss P (1998) Differential distribution of gelatinases and tissue inhibitor of metalloproteinase-1 in the rat ovary fournal of Endocrinology 158 221-228

Behboodi E, Anderson GB, Bondurant RH, Cargill SL, Kreuscher BR, Medrano JF and Murray JD (1995) Birth of large calves that developed from in vitro derived embryos Theriogenology 44 227-232

Braw-Tal $\mathbf{R}$ and Yossefi $\mathbf{S}$ (1997) Studies in vivo and in vitro on the initiation of follicle growth in the bovine ovary Journal of Reproduction and Fertility 109 165-171

Cecconi S, Barboni B, Coccia M and Mattioli M (1999) In vitro development oi sheep preantral follicles Biology of Reproduction 60 594-601

Cortvrindt R, Smitz / and van Steirtegham AC (1996) in vitro maturation, fertilization and embryo development of immature oocytes from early preantral follicles from prepubertal mice in a simplified culture system Human Reproduction 12 2656-2666

Daniel SA, Armstrong DT and Gore-Langton RE (1989) Growth and development of rat oocytes in vitro. Gamete Research 24 109-121

Eppig II (1994) Further reflections on culture systems for the growth of oocytes in vitro. Human Reproduction 9 969-976

Eppig IJ and O'Brien MJ (1996) Development in vitro of mouse oocytes from primordial follicles Biology of Reproduction 54 197-207

Eppig II and $\mathrm{O}^{\prime} B r i e n$ MJ (1998) Comparison of preimplantation developmental competence after mouse oocyte growth development in vitro and in vivo. Theriogenology $49415-422$

Eppig If and Schroeder AC (1989) Capacity of mouse oocytes from preantral follicles to undergo embryogenesis and development to live young after growth, maturation, and fertilization in vitro. Biology of Reproduction $41268-276$

Eppig II and Telfer EE (1993) Isolation and culture of oocytes Methods in Enzymology 225 77-84

Erickson BH (1966) Development and senescence of the postratal bovine ovary journal of Animal Science 25 800-805
Faddy MJ, Telfer EE and Gosden RG (1987) The kinetics of preantral follicle development in ovaries of CBAVCa mice during the first 14 weeks of life Cell and Tissue Kinetics $20551-560$

Fortune JE, Kito S and Wandji SA (1998) Activation of bovine and baboon primordial follicles in vitro. Theriogenology $49441-449$

Gosden RG and Telfer E (1987a) Scaling of follicular sizes in mammalian ovaries Journal of Zoology 211 157-168

Gosden RG and Telfer E (1987b) Numbers of follicles and oocytes in mammalian ovaries and their allometric relationships fournal of Zoology 211 169-175

Greenwald GS and Moor RM (1989) Isolation and preliminary characterization of pig primordial follicles Journal of Reproduction and Fentility 87 561-571

Gutierrez C, Ralph JH, Telfer EE, Wilmut I and Webb R (2000) Growth and antrum formation of bovine preantral follicles in long-term culture Biology of Reproduction 62 1322-1328

Herlands RL and Schultz RM (1984) Regulation of mouse oocyte growth: probable nutritional role for intercellular communication between follicle cells and oocytes in oocyte growth fournal of Experimental Zoology 229 $317-325$

Hirao Y, Nagai T, Kubo M, Miyano T and Kato $S$ (1994) In vitro growth and maturation of pig oocytes fournal of Reproduction and Fertility $100333-339$

Jones EC and Krohn PL (1961) The relationship between age and numbers of oocytes and fertility in virgin and multiparous mice Journal of Endocrinology 21 469-495

McCaffery FH, Leask R, Riley SC and Telfer EE (2000) Culture of bovine preantral íllicles in a serum free system: markers for assessment of growth and development Biology of Reproduction 63 267-273

Nathanielsz PW (1999) Life in the Womb: the Origin of Health and Disease Promethean Press, Ithaca

Nayudu PL and Osborn SM (1992) Factors influencing the rate of preantral and antral growth of mouse ovarian follicles in vitro. Journal of Reproduction and Fertility 95 349-362

Newton $\mathbf{H}$, Picton $\mathbf{H}$ and Gosden RG (1999) In vitro growth of oocyte-granulosa cell complexes isolated from cryopreserved ovine tissue Journal of Reproduction and Fertility 115 141-150 
Roy SK and Greenwald CS (1985) An enzymatic method for dissociation of intact follicles from the hamster ovary: histological and quantitative aspects Biology of Reproduction 32 203-215

Roy SK and Greenwald GS (1989) Hormonal requirements for the growth and differentiation of hamster preantral follicles in long-term culture Journal of Reproduction and Fertility 87 103-114

Sinclair KD, McEvoy TG, Maxfield EK, Maltin CA, Young LE, Wilmut I, Broadbent PJ and Robinson J (1999) Aberrant fetal growth and development after in vitro culture of sheep zygotes Journal of Reproduction and Fertility 116 177-186

Smith GW, Goetz TL, Anthony RV and Smith MF (1994) Molecular cloning of an ovine ovarian tissue inhibitor of metalloproteinases: ontogeny of mRNA expression and in situ localisation within preovulatory follicles and luteal tissue Endocrinology 134 344-352

Spears N, Boland NI, Murray AA and Gosden RG (1994) Mouse oocytes derived from in vitro grown primary ovarian follicles are fertile Human Reproduction 9 527-532

Telfer EE (1996) The development of methods for isolation and culture of preantral follicles from bovine and porcine ovaries Theriogenology 45 101-110

Telfer EE (1998) in vitro models for oocyte development Theriogenology $49451-460$

Telfer EE and Watson ED (2000) Isolation of preantral follicles from mare ovaries Journal of Reproduction and Fertility Supplement 56 447-453

Telfer EE, Binnie JP and Jordan LB (1998) Effect of follicle size on the onset of apoptotic cell death in cultured bovine ovarian follicles Theriogenology $49 \quad 357$ (Abstract)

Telfer EE, Webb R, Moor RM and Gosden RG (1999) New approaches to increasing oocyte yield from ruminants Animal Science 68 285-298

Telfer EE, Binnie JP, McCaffery $F$ and Campbell BK (2000) in vitro development of oocytes from porcine and bovine primary follicles Molecular and Cellular Endocrinology $163117-123$

Thomas FH, Leask R, Sršen V, Riley SC, Spears N and Jelfer EE (2001) Effect of ascorbic acid on health and morphology of bovine preantral follicles during longterm culture Reproduction $122487-495$

Thompson JG (1997) Comparison between in vivo derived and in vitro produced pre-elongation embryos from domestic ruminants Reproduction, Fertility and Development 9 341-354

Torrance C, Telfer E and Gosden RG (1989) Quantitative study of the development of isolated mouse pre-antral follicles in collagen gel culture journal of Reproduction and Fertility 87 367-374

Van den Hurk R, Spek ER, Hage WJ, Fair T, Ralph JH and Schotanus K (1998) Ultrastructure and viability of isolated bovine preantral follicles Human Reproduction Update 4 833-841

Van den Hurk R, Abir R, Telfer EE and Bevers MM (2000) Primate and bovine immature oocytes and follicles as sources of fertilisable oocytes Human Reproduction Update $6457-474$

Vanderhyden BC, Telfer EE and Eppig || (1992) Mouse oocytes promote the proliferation of granulosa cells from preantral and antral follicles in vitro. Biology of Reproduction 46 1196-1204

Walker SK, Heard TM and Seamark RF (1992) in vitro culture of sheep embryos without co-culture: successes and perspectives Theriogenology 37 111-126

Walker SK, Hartwich KM and Seamark RF (1996) The production of unusually large offspring following embryo manipulation: concepts and challenges Theriogenology 45 111-120

Willadsen SM, Janzen RE, McAllister RJ, Shea BF, Hamilton C and McDermand D (1991) The viability of late morulae and blastocysts produced by nuclear transplantation in cattle Theriogenology 36 161-170

Wright CS, Hovatta O, Margtara R, Trew G, Winston RM, Franks S and Mardy K (1999) Effects of folliclestimulating hormone and serum substitution on the in-vitro growth of human ovarian follicles Human Reproduction 14 1555-1562

Wu J, Emery BR and Carrell DT (2000) in vitro growth, maturation, fertilization, and embryonic development of oocytes from porcine preantral follicles Biology of Reproduction 64 375-381

Young LE, Sinclair KD and Wilmut I (1998) Large ofíspring syndrome in cattle and sheep Reviews of Reproduction 3 155-163

Zhao $Y$ and Luck MR, (1996) Bovine granulosa cells express ECM proteins and their regulators during luteinisation in culture Reproduction, Fertility and Development 8 259-226 